Public Insurance and Equality

From Redistribution to Relation

Landes, Xavier; Néron, Pierre-Yves

Published in:

Res Publica

DOI:

10.1007/s11158-015-9269-y

Publication date:

2015

Document version

Early version, also known as pre-print

Citation for published version (APA):

Landes, X., \& Néron, P-Y. (2015). Public Insurance and Equality: From Redistribution to Relation. Res Publica, 21(2), 137-154. https://doi.org/10.1007/s11158-015-9269-y 


\title{
Public Insurance and Equality: From Redistribution to Relation
}

\section{This version is the authors' version. The final publication is available on the website of} Res Publica at:

\section{http://link.springer.com/article/10.1007/s11158-015-9269-y}

\author{
Xavier Landes \\ University of Copenhagen, Department of Media, Cognition and Communication \\ Karen Blixens Vej 4, 2300 København S, Denmark \\ +45 20715415, xavier.landes@gmail.com \\ Pierre-Yves Néron \\ Université Catholique de Lille, Département d'éthique et institut de philosophie \\ 60 boulevard Vauban - BP109, 59016 Lille CEDEX, France \\ +33699915858, pierre-yves.neron@icl-lille.fr
}

\begin{abstract}
Public insurance is commonly assimilated with redistributive tools mobilized by the welfare state in the pursuit of an egalitarian ideal. This view contains some truth, since the result of insurance, at a given moment, is the redistribution of resources from the lucky to unlucky. However, Joseph Heath (among other political theorists) considers that the principle of efficiency provides a better normative explanation and justification of public insurance than the egalitarian account. According to this view, the fact that the state is involved in the provision of specific insurance (primarily health and unemployment insurance and pensions) is explained and justified by the greater efficiency of the state, in comparison with markets, in addressing market failures such as moral hazard or adverse selection.

Our argument is that while insurance, intrinsically and idealistically, may diverge from a redistributive scheme, it is nevertheless difficult to deny that insurance has nothing to do with equality. More precisely, we argue that insurance may be understood as an egalitarian tool if our understanding of equality is broadened to include relational equality.

Our paper aims to briefly recap the debates surrounding public insurance as a redistributive tool, advancing the idea that public insurance may be a relational egalitarian tool. It then presents a number of relational arguments in favor of the involvement of the state in the provision of specific forms of insurance, arguments that have been overlooked given the domination of luck egalitarian approaches in these debates.
\end{abstract}

\section{Keywords}

Luck Egalitarianism; Public Insurance; Redistribution; Welfare State; Relational Egalitarianism 


\section{Introduction}

Justifications of the welfare state have been at the center of heated debates in political philosophy. It is common to present these debates between supporters and critics of the welfare state as a conflict between equality and efficiency (Okun 1975). There is, however, another way to frame certain debates about the role of public institutions in industrialized societies. This involves interpreting such debates as a conversation about conditions for efficiency and the proper balance between public and private arrangements needed to maximize such efficiency.

Various political theorists have suggested that debates surrounding the welfare state make much more sense if they are understood as being about efficiency, and not as a stark confrontation between equality and efficiency (Goodin 1988; Moss 2002). In part, their point is to emphasize that some features of the welfare state have less to do with equality than they do with efficiency. In particular, Joseph Heath makes the double claim that insurance is at the core of the welfare state and that the former is less concerned with equality or community than it is with efficiency (Heath 2011). It therefore follows that justifications of the welfare state should be efficiency-based.

In this paper, we investigate the meanings and philosophical underpinnings behind the creation of 'communities of insureds' (Stone 1999-2000). While recognizing the value of contributions from Robert Goodin, Joseph Heath, David Moss and others - who maintain that public insurance is a matter of efficiency that fits imperfectly with redistributive theories - we nonetheless argue that it is possible to provide an egalitarian reading of public insurance, one that could complement the efficiency account. We claim that public insurance can also be explained and justified by egalitarian arguments that are distinct from distributive arguments, in 
particular luck egalitarianism, which figures among the most prominent, if not the most prominent, formulations of the distributive ideal. We assert that public insurance can be explained and justified by relational egalitarianism. ${ }^{1}$

Despite its critical tone, our paper is neither a rejection of Heath's argument (or the more general claim about the role of efficiency in justifications of the welfare state and public insurance), nor a dismissal of luck egalitarianism as a convincing doctrine of distributive justice. We simply argue that both efficiency and redistributive luck egalitarian arguments present a partial defense of public insurance that requires complementary, and to some extent, stronger arguments.

One caveat before we begin. By public insurance, we mean an insurance scheme that (1) is funded and owned by the state; (2) covers social risks typically identified as health, unemployment and retirement; and (3) is compulsory. ${ }^{2}$ This loose definition has the advantage of coinciding with the archetypical welfare systems found in countries such as France, Canada and the United Kingdom. In addition, many countries partly match this broad description, in the sense that the state covers part of the abovementioned social risks, with some components of social insurance being undertaken or completed by institutions other than the state and its agencies.

Our argument is that relational egalitarianism provides compelling justifications for public insurance, i.e. insurance undertaken by public institutions. To present this argument, the article is divided into three sections. The first section presents the argument that insurance

\footnotetext{
${ }^{1}$ Despite the fact that any egalitarian position might be qualified as relational (since equality is a relational concept), here we follow the general acceptation in the literature that relational egalitarianism is distinctly relational in the sense that it views equality as norm for the evaluation of social relationships. The relational egalitarianism label is now increasingly used in the literature. See, for instance, Anderson's recent works (Anderson 2009, 2010).

2 This definition overlaps more or less fully with definitions provided by other authors (Shapiro 2007, p. 11).
} 
is not a redistributive mechanism, and hence not an egalitarian device on redistributive grounds. The second section partly supports this claim by discussing one of the major distributive theories in political philosophy: luck egalitarianism (hereafter LE). ${ }^{3}$ We claim that LE fails to provide a full explanation of, and justification for, public insurance mechanisms. The third section advances the idea that, while public insurance may be not egalitarian in a redistributive sense, relational egalitarianism (as defended by authors such as Elizabeth Anderson, Jonathan Wolff and Samuel Scheffler) still provides strong egalitarian arguments in favor of public insurance.

\section{Insurance as a Non-Redistributive Mechanism}

Insurance mechanisms are at the core of the modern welfare state. Depending on the country, they include services such as health insurance, unemployment benefits and pensions. Therefore, a widespread intuition is that public insurance constitutes a powerful tool for pursuing redistributive, hence egalitarian, purposes. In principle, by compensating citizens for the loss of their job, the costs induced by illness, or being too old to work, public insurance transfers resources from the lucky to unlucky. In other words, in principle, public insurance is a redistributive tool.

Certain authors such as Goodin or Heath challenge this intuition by claiming that neither private nor public insurance is an intrinsically redistributive mechanism. There are several ways to substantiate the claim, one being that proper insurance, in other words insurance based on actuarial principles (i.e. contributions being adjusted to expected losses), does not

\footnotetext{
${ }^{3}$ To be clear, we do not intend to rebut LE as a consistent doctrine of distributive justice. LE may be a perfectly sound theory of redistribution; there is no quarrel about that. Our aim is to launch discussions on the difficulties experienced by LE as it is generally understood in explaining and justifying public insurance and the welfare state.
} 
change the expected utility of the policyholders (Landes 2013a). Individuals should not gain in expected terms from the insurance. If they do, this may cause a moral problem, such as in adverse-selection cases (Landes 2013b). The only service that is provided by the insurance mechanism is to reduce the standard deviation, i.e. to remove uncertainty.

In a recent article, Joseph Heath provides an account of various justifications for the welfare state (Heath 2011). He identifies three models: the egalitarian/redistributive model (the state does/should reduce inequality); the communitarian model (the state does/should enforce a specific conception of the community); and the efficiency model (the state does/should improve social cooperation). He is pressing the point that redistributive and communitarian arguments fail to pass a double test, which is explanatory and justificatory.

A theory succeeds in passing the explanatory test if it furnishes a plausible account of why state expenditure has seen constant growth since the nineteenth century, independently of the political color of the government (a phenomenon often presented as 'Wagner's Law'). In order to pass this test and provide what Heath calls a plausible 'normative reconstruction', neither the pursuit of redistributive equality nor the spirit of community could provide such plausible reasons. Heath argues that only an explanatory scheme focused on the state's efficiency in handling collective action problems could explain this constant growth. The idea is that state efficiency in handling collective action problems (e.g. moral hazard and adverse selection in the field of insurance) explains such growth. In short, public spending has been on the rise because the state is more efficient than private actors in undertaking certain activities.

A theory succeeds in passing the justificatory test if it furnishes solid justificatory reasons for the actual functions of the state, and in particular its welfare activities. Among those functions, social insurance is central. Heath's major point is that neither the redistributive account (identified with authors such as John Rawls or Ronald Dworkin), nor the communitari- 
an account (embodied by theorists such as Michael Sandel or Michael Walzer) can justify why the state should provide what is usually thought to fall within the scope of public insurance, namely health insurance, unemployment benefits and pensions. The foundation of his claim is that the communitarian account has an overly extensive view of the role of the state, one that would lead to invasive interference in public life, while the redistributive account draws an overly strict line between redistribution and allocation, with the former falling within the competence of the state and the latter being the responsibility of markets and corporations.

With his emphasis on state efficiency in managing various forms of insurance, Heath feeds into a body of literature in North America that wishes to recode the debate between libertarians/classical liberals and egalitarians, a debate that is traditionally (mis)understood as opposing efficiency and equality. For example, David Moss argues that the main role of the state is to manage risks, and that this role is explained and justified because the state is more efficient than free markets in handling information problems such as moral hazard or asymmetry of information (Moss 2002, 2007-2008). This efficiency originates in tools that only the state possesses, including law (compulsory enrolment in insurance schemes, thereby avoiding adverse selection; regulations that address moral hazard); monitoring capacities (through various state agencies such as safety and social services); force (police, army); and broader financial resources (through public taxation, the ability to raise massive capital, etc.).

Indeed, Moss's and Heath's justifications are directly in line with arguments advanced by the (New) Welfare Economics approach, which identifies the management of market failures, primarily externalities, as the main justification for the place of public institutions in modern economies (Baumol 1952, 1972). By doing so, they strive to replace the simplistic dichotomy between efficiency and equality (Okun 1975) with a more sophisticated view that 
does justice to the role played by public institutions in producing or strengthening efficiency.

This focus on efficiency for both explanatory and justificatory purposes explains the particular structure of Heath's argument, which combines empirical and normative claims. His argument can be summarized as follows:

(1) Insurance is a central function of the welfare state;

(2) Insurance largely explains the rise and development of the welfare state;

(3) The efficiency of the state in managing insurance justifies such development;

(4) This role cannot be explained and justified by relying (only) on redistributive or communitarian arguments;

(5) Efficiency arguments are therefore necessary to provide both an explanation and a justification for the state's involvement in insurance, i.e. public insurance. In other words, 'the real driving force behind existing public health care systems is not a general concern about equality, but rather market failure in the health insurance sector. The "normative logic" of these systems is one of efficiency' (Heath 2011, p.35).

Heath may be right about the role played by efficiency in the growth of the welfare state. ${ }^{4}$ The history of proto-social insurance offered by friendly societies and the mutual movement in France (Ewald 1986, 1996), the United Kingdom (Cordery 2003) and the United States (Beito 2000) supports his claim. This history highlights the fact that the replacement of private entities (unions, fraternal societies, sociétés de secours mutuel, etc.) with publicly subsidized or managed insurance organizations in the provision of social insurance (life insurance, pensions, sickness benefits, etc.) resulted both from the refusal of these private entities to use ac-

\footnotetext{
${ }^{4}$ Heath adheres to a Paretian conception of efficiency: a state of affairs is Pareto-optimal if the situation of any agent could be improved without undermining the situation of another agent.
} 
tuarial knowledge (which would have enabled a better evaluation of risks), and from their limited financial resources, which became particularly acute during the recession of the 1930s. Therefore, the efficiency of the state as the last-resort insurer was a powerful driving force behind the increased role of public institutions in modern economies.

Furthermore, Heath is right to assert that efficiency constitutes solid grounds for justifying and not only explaining public involvement in the provision of insurance such as health and unemployment benefits or pensions. His point is important because it breaks the false dichotomy between pro-welfare-state arguments, which are seen to be inherently redistributive or communitarian, and pro-market arguments, which are seen to be inherently about efficiency. We suggest, however, that other normative narratives help explain and justify the role of the welfare state in the provision of public insurance. Egalitarian, and perhaps communitarian, reasons offer a complementary rationale for public insurance.

The two forthcoming sections make a double case. The second section illustrates the difficulties that distributive conceptions of equality experience in justifying public insurance, something which supports Heath's view. But, unlike Heath, the third section presents arguments as to why such difficulties do not disqualify all egalitarian theories. In particular, relational conceptions (and the like) offer both an explanation and a justification. As such, they mitigate Heath's rebuttal of egalitarian/redistributive and communitarian justifications for public insurance and the welfare state.

\section{The Luck Egalitarian Case for Public Insurance}

Heath's critique of the egalitarian case for public insurance appears to be based upon a restricted understanding of what kind of egalitarian instrument it is. Namely, he tends to reduce egalitarian mechanisms to redistributive mechanisms, disregarding the very possibility of a 
device being egalitarian in a non-redistributive sense.

The purpose of this section is to support the idea that public insurance is not redistributive (while still being egalitarian, though in a different sense). It does this through a brief discussion of one of the most popular accounts of distributive justice: luck egalitarianism, understood as the set of theories sharing the premise that redistribution of resources should acknowledge the split between choices and circumstances.

Another important reason for discussing LE is that its fundamental logic seems to mimic insurance mechanisms, i.e. resources being transferred from the lucky to the unlucky, strongly suggesting that insurance actually compensates for lack of luck (something LE advocates). Therefore, in addition to constituting a major group of redistributive theories, approaches based on LE appear able to account for insurance mechanisms.

LE articulates two claims: (1) a responsibility claim, and (2) a redistributive claim. They are related in the sense that, a priori, a certain response to (1) gives a prima facie reason for activating (2). Considering this broad framework, we argue that the responsibility claim poses a problem for the LE justification of insurance and, as a result, for redistributive reasons for public insurance that are based on a (very) broad LE rationale.

The two claims can be formulated as it follows:

(1) The responsibility claim is that individuals are not responsible for inequalities that stem from circumstances. The corollary claim is that individuals are responsible for other inequalities (the assumption being that choices and circumstances exhaust all sources of inequalities).

(2) The redistributive claim is that individuals are entitled to compensation for inequalities that stem from circumstances. The corollary claim is that individuals are not enti- 
tled to compensation for other inequalities. ${ }^{5}$

The reason why this general formulation is labelled as LE is that the domain of equality (i.e. redistribution) is determined by luck. Yet, in general, only some kinds of luck are presented as being an object of redistribution: brute bad luck (i.e. circumstances) is thought to activate the redistributive claim, while bad-option luck (i.e. choices) is not. As Shlomi Segall puts it, 'luck egalitarianism is essentially the idea that it is unfair for one person to be worse off than another due to reasons beyond her control' (Segall 2010, p. 10). ${ }^{6}$ Segall goes on to affirm that 'it is unjust for individuals to be worse off than others due to outcomes that it would have been unreasonable to expect them to avoid' (Segall 2010, p. 13).

\section{Luck Egalitarianism as an Explanatory Framework}

Intuitively, this scheme seems to fit the actual functioning of both private and public insurance. As mentioned above, insurance is usually presented as a redistributive mechanism from lucky to unlucky policyholders. And this may be used to support the claim that insurance is a redistributive tool that more or less follows an LE rationale.

But any argument in favor of public insurance based on this rationale faces a serious problem embodied in the choice/circumstance distinction. The fact is that insurance, whether public or private, actually compensates individuals in case of loss stemming from either choice or circumstances (and so reduces ensuing inequalities), as long as they are insured against risks generating inequalities. Moreover, public insurance does not compensate for in-

\footnotetext{
${ }^{5}$ Individuals might, however, be entitled to compensation for reasons other than justice, if we include another normative consideration as some proponents of LE aim to do. We deal with this issue later in this paper.

${ }^{6}$ The reader will find numerous variations of this idea (Dworkin 2002; Knight 2009). For instance, Susan Hurley writes that 'egalitarianism should aim to neutralize differences due to luck, for which people are not responsible ... But it should not aim to neutralize differences due to choice' (Hurley 2003, p. 141).
} 
equalities in the sense that it leaves previous inequalities (i.e. before the actualization of risks) untouched (even if other features of the welfare state might address these inequalities).

One may well acknowledge that insurance covers choice-sensitive risks along with choice-insensitive risks, but still argue that access and/or degree of compensation depends on individual responsibility. Two features of insurance strengthen this counter-objection.

Firstly, in an actuarially sound insurance scheme, premiums are correlated to (if not directly calculated on the basis of) risk exposure (i.e. expected losses resulting from the probabilities of adverse events and their expected amplitude). Insurance mechanisms therefore track individual responsibility, since high-risk exposure would translate into higher premiums (Landes 2014).

Secondly, insurance usually imposes various constraints on compensation. For instance, deductibles, co-insurance or co-payments make policyholders co-responsible for their losses with the insurer (i.e. the rest of the community). Requirements are also imposed on policyholders to be eligible for compensation (e.g. the installation of additional locks or an alarm for burglary insurance, a smoke detector for fire insurance, etc.).

Thus, while insurance does not rely on the choice/circumstance split (i.e. the division between option luck and brute luck) to exclude individuals from the benefits of risk-pooling, individual responsibility still matters when it comes to compensation.

In response to the first point, it might be said that actuarial fairness requires underwriting all sorts of risk. To calculate individual premiums, all factors relevant to risk exposure are usually underwritten, many of which are obviously outside one's sphere of responsibility (no matter how responsibility is defined), such as age, gender, ethnicity, family antecedents, etc. So it is inaccurate to affirm that risk premiums account for individual responsibility, since to a large extent risk exposure may be independent of individual responsibility. 
In response to the second point, it may be argued that the limitations imposed on compensation exist for risks that are choice-dependent (e.g. motor insurance) as well as for risks that may be choice-independent (e.g. structural or cyclical unemployment or health risks related to genetic diseases). In other words, insurance mechanisms under actuarially fair operations do not recognize the split between choices and circumstances.

Moreover, insurance operates by classifying risks and sorting individuals into risk classes according to demographic or personal characteristics that are statistically relevant for the risk covered (e.g. age, gender, residence, lifestyle). As a result, everyone has to pay premiums reflecting the risk exposure of the risk class to which she belongs, and not strictly individualized risk exposure.

To sum up, it seems difficult to prove the intuition that a general LE rationale closely mimics insurance practices and, as such, captures the inner logic of insurance. An open question remains as to whether other versions of egalitarianism (combined with a concern for efficiency, for instance) may be less vulnerable to the objections raised in this section. But the case remains that a defense of public insurance based on a strict LE rationale encounters difficulties in justifying public (and private) insurance.

\section{Luck Egalitarianism as a Justificatory Framework}

In response to our previous criticism, it may be objected that the purpose of the debate is to determine how LE could justify public insurance, and how LE principles could translate into public insurance arrangements, rather than to show how the general functioning of public insurance matches the LE rationale as formulated in this article. For the sake of discussion, two versions of the LE argument are distinguished.

Luck egalitarianism 1 (LE1): compensation through public insurance should be 
allowed for risks that are choice-independent, while risks that are choice-dependent should not be compensated.

An obvious problem with LE1 is that it excludes from the scope of risk-pooling most risks that are at the heart of public insurance, or that it could dramatically alter the operation of public insurance. For instance, health issues stem in large part from individual life choices (e.g. food habits, smoking, lack of exercise, etc.). Unemployment may be considered voluntary in the double sense that individuals may either contrive to lose their job or to stay unemployed. ${ }^{7}$

The 'responsibility assessment' implied by LE1 encounters two kinds of difficulties. The first kinds of difficulties are epistemic. Because risks are often a subtle mix of choices and circumstances, attempts to disentangle such a mix are mostly arbitrary (from the perspective of actual causation). ${ }^{8}$ This is a central point since such difficulties were at the origins of public insurance and many crucial institutional developments (Cordery 2003; Ewald 1986). The second kinds of difficulties are moral. If one tries to determine a policyholder's entitlement on a case-by-case basis, i.e. by determining if in this precise case the policyholder is responsible for his situation, this may lead to intrusive and demeaning policies (Wolff 1998).

However, one may find a second version of LE more attractive.

Luck egalitarianism 2 (LE2): compensation through public insurance should be modulated in regard to the degree of individual responsibility.

Unlike LE1, LE2 does not exclude policyholders from compensation on the basis of their own degree of responsibility (which would contradict the universal scope of public insurance). In-

\footnotetext{
${ }^{7}$ Pensions present a more difficult case to make on luck egalitarian grounds, so we will leave them aside for the moment.

${ }^{8}$ This point is acknowledged by certain luck egalitarians (Segall 2010, p. 62).
} 
stead, individual responsibility determines the level of their premiums or compensation. Many public health insurance systems are moving in the direction of individual re-responsibilisation (Gladwell 2005). For public health insurance, co-payments have been introduced for doctor's consultations and various medical acts (e.g. in France).

Consequently, one way to express the rationale embodied in LE2 is that everyone is entitled to public insurance but not under the same terms, such terms being determined by individual responsibility. For example, patients who suffer from congenital diseases would be entitled to full support while smokers who suffer from smoking-related cancers, or overweight persons who request a gastric ring, would be entitled to only partial support reflecting what is left once their share of responsibility is subtracted from the losses.

This second version of LE provokes several remarks. Firstly, LE2 faces exactly the same epistemic and moral difficulties as LE1. For health and unemployment, most risks result from subtle combinations of choices and circumstances. ${ }^{9}$ Imagine that two individuals, who have been smoking the same quantity of tobacco during the same period of time, develop the same cancer. However, due to genetic predispositions one is cured after few months of chemotherapy while the other undergoes chemotherapy and expensive treatment for several years without any health improvement. What is their respective level of material responsibility?

This question is far from trivial in terms of LE support of public insurance: failing to track individual responsibility may lead to disadvantaging individuals on the basis of their

\footnotetext{
${ }^{9}$ One may argue that if LE is accurate, society should move as close as possible to the LE ideal by relaxing, for instance, the responsibility requirement in most cases involving public insurance (such as health or unemployment). This what Voigt has in mind when she argues that it is unlikely that there will be any realworld cases in which the luck egalitarian would not have to provide at least partial compensation (Voigt 2007). However, this answer relies on suspending the central feature of LE, namely the conditionality of the redistributive claim on the responsibility claim. In short, such a solution does not bring society closer to the LE ideal, but moves it further away.
} 
circumstances, which represents a failure of the LE project, premised as it is on the moral significance of the split between choices and circumstances. In addition, LE2 faces the same moral objection as LE1: the necessity of proving that one's fate is, even partly, due to brute luck (and not option luck or choice) may be perceived as demeaning, humiliating or insulting (Wolff 1998)..$^{10}$

Moreover, and this is a crucial argument in this paper, the challenge that the responsibility claim levels at an egalitarian theory goes beyond the aforementioned epistemic and moral difficulties. Considered in terms of the history of the welfare state and the rise of public insurance in the nineteenth and twentieth centuries, the central role played by individual responsibility in the LE rationale seems archaic. Trying to trace individual responsibility within a public insurance scheme represents a step back from the very reason why social insurance first emerged. ${ }^{11}$

Social insurance, i.e. insurance that covers risks that that were later assimilated into public insurance (e.g. sickness, unemployment, ageing and, sometimes, accidents), emerged and more importantly spread under the impulsion of states as a solution to the difficulty of tracking individual responsibility (Ewald 1986). Because individual responsibility was difficult or impossible to determine in many cases of illness, accident, unemployment (and presumably, the incapacity to work because of old age), insurance mechanisms based on collective responsibility were implemented and promoted by both private and public actors. The

\footnotetext{
${ }^{10} \mathrm{We}$ are aware that these problems have already been highlighted in the significant literature on LE and its critics (see, for example, Knight 2005; Voigt 2007). Our point here is that public insurance magnifies them.

11 One might object that this empirical account does not have any normative force. We nevertheless think that it does matter normatively. As explained above, we are following Heath in his suggestion that a full normative theory of the welfare state needs to provide both justificatory and explanatory 'stories'. As Heath puts it, the empirical/historical account of the rise of public insurance offers us a 'reconstructive' story, in the Habermasian sense, i.e. it helps articulate implicit norms and ideals that play a structuring role in our existing practices (Heath 2011, p. 28).
} 
history of fraternities, sociétés de secours mutuel and the mutual movement demonstrate that insurance has been an institutional response to both the epistemic difficulties posed by individual responsibility (Anderson, forthcoming; Ewald 1986, 1996; Goodin 1988) and, arguably, the moral difficulties too (Landes 2013c). The epistemic difficulties highlight the case made by Heath or Goodin in favor of the substitution of collective responsibility for individual responsibility: the collective responsibility embodied in insurance, especially in its public form, represents an efficiency improvement. Indeed, a regime of collective responsibility lowers monitoring and litigation costs (Goodin 1998, p. 157). In this respect, LE, understood as basing redistributive claims on responsibility claims, undermines the solution of collective responsibility embodied in public insurance.

Our point is that citizens already make most 'voluntary' decisions in a complex web of pre-existing insurance mechanisms that render responsibility assessment and tracking, in the way LE suggests, almost impossible. Hence, if we follow Ewald and others, the growth of insurance since the nineteenth century challenges the very possibility of thinking about responsibility in the manner LE proposes.

This does not represent a fatal defect per se for LE. It may be considered that public insurance should, in one way or another, be rendered sensitive to individual responsibility. Furthermore, sound arguments could be brought forward in favor of such reform, for instance that individuals should not pay for risks they are not responsible for (namely other people's risks), or the risks to the financial stability of public insurance arising from the possibility of externalizing choice-sensitive costs from the unlucky to the lucky.

These various difficulties nonetheless give weight to complaints made by critics of LE, who argue that its policy recommendations are often unappealing for the following three broad reasons: (1) harshness: LE allows individuals who make reasonable but ultimately un- 
lucky choices to become deprived (Anderson 1999); (2) humiliation: LE-based reforms can humiliate the disadvantaged by branding them as stupid or talentless (Anderson 1999; Wolff 1998); and (3) over-personalization: by emphasizing the choice/circumstance distinction, LE is guilty of an over-personalization of situations and therefore fails to integrate a perspective on how both structural patterns and complex webs of social relations create inequalities, and on how we make choices within already existing insurance schemes (Kibe 2011; Rosanvallon 2013). These three difficulties render LE unable to provide a satisfactory justificatory account of public insurance. ${ }^{12}$

LE theorists may reply by arguing that their theory can be complemented by other moral considerations, such as humanitarian ones or a 'solidarity' principle which states that people made worse off by their voluntary decisions should not be abandoned (Segall 2007). This is an interesting proposal. However, though it helps to show that the impact of the LE rationale may be lessened for victims of bad-option luck, the addition of such a solidarity component does not help us justify and explain the state's significant involvement in insurance from a strict LE perspective. In other words, such an addition is both independent of the LE framework and fails to provide an explanation and justification for the rise of public insurance. ${ }^{13}$

The difficulties generated by LE suggest a need to investigate other theoretical frameworks in search of comparative advantages offered by other forms of egalitarianism. More

\footnotetext{
12 Here it is worth taking a few steps back to note that by insisting on a harsh distinction between choice and circumstances, LE opens the door to the classical conservative views on insurance, according to which insurance, because of moral hazard, creates individual incentives to be lax about avoiding harms and to make irresponsible decisions. While proponents of LE, unlike conservatives, do not insist on this point about incentives to make irresponsible decisions, both nonetheless deplore compensation for them.

${ }^{13}$ It could be argued that a merit of any distributive theory lies in its capacity to accommodate other goods. In other words, pluralism in the form of the integration of independent values is worthy of praise (see further Segall's reply to the abandonment objection [Segall, 2010]). However, what is judged in these pages is the intrinsic capacity of LE to justify public insurance, not its capacity to be compatible with external reasons that could lead to such a justification.
} 
precisely, we argue that relational egalitarianism conceives the intrusion into people's lives to check their level of responsibility as a lack of respect and a violation of the 'egalitarian ethos' (Wolff 1998). A priori, relational egalitarianism seems to offer a fresh way of thinking about the egalitarian grounds for public insurance without mobilizing the choice/circumstance split. In addition, this enquiry into relational egalitarianism may offer arguments that challenge Heath's view of insurance as a cooperative mechanism that can be neither explained nor justified by egalitarian/redistributive or communitarian arguments.

\section{The Relational Case for Public Insurance}

In this section, we argue that in order to have a fuller account of public insurance and its egalitarian dimensions, we need to draw on the insights of relational egalitarianism. We will argue that such an approach allows us to view the creation of a 'community of insureds' as a genuine egalitarian project. Furthermore, we will briefly introduce the idea of public insurance as delivering such a project. In short, we advance relational arguments for public insurance that (1) cannot be accounted for in the LE account, and (2) prove that Heath's view of insurance is incomplete.

Recent debates in egalitarian thought broadly oppose LE and relational egalitarianism (or 'social relations egalitarianism'), according to which the norms of egalitarian justice require, and are satisfied by, a society in which individuals relate to one another as equals (Scheffler 2010). For the sake of this paper, we adopt a broad interpretation of relational egalitarianism in an attempt to achieve some distance from the now dominant LE.

We suggest that relational egalitarianism draws on four main insights (Néron 2014). ${ }^{14}$

\footnotetext{
14 We rely here on an account of relational egalitarianism articulated by one of the authors of this paper in a separate article (Néron 2014). The literature on this debate is growing. For recent contributions, see also Fourie (2012) Fourie, Schuppert and Walliman-Hellmer (2015), Garrau and Laborde (2015).
} 
First, to seek more equal distribution is not an end itself but rather a tool to achieve the goal of creating and sustaining more equal social relations between individuals and groups. Second, the focus on the distribution of resources or welfare alone does not adequately capture, or at least only partially, the projects and discourses of real egalitarian political movements. Third, inequalities emerge from hierarchical social relations among individuals organized along lines of group identity such as race, class and gender (Anderson 2009, 2010). Building on Marx's insight that 'society does not consist of individuals, but expresses the sum of interrelations, the relations within which these individuals stand' (Marx 1993, p. 265), relational egalitarians focus not only on how human action is embedded in complex networks of social and economic relations, but also on how these relations are the primary sources of inequalities (Anderson 2010; Kibe 2011, p. 3). Fourth, egalitarianism, as Wolff suggests, does not consist mainly in justifying principles for distributing resources, but rather it starts with an egalitarian 'ethos', a collection of values and attitudes associated with a commitment to develop equal relationships (and goes hand in hand with an attempt to identify and criticize values and attitudes that represent a clear departure from such a commitment) (Wolff 1998, 2010).

\section{Relational Egalitarianism as a Justificatory Strategy}

Given the departure from a strict focus on distributional concerns, 'relationists' are more inclined than luck egalitarians to accept that there might be a conflict between the fairness of distributive outcomes and the goal of promoting and sustaining equal respect. This tension is at the heart of Anderson and Wolff's argument that the responsibility element incorporated into LE suggests a sharp distinction between those who are responsible for their difficulties and those who are not, and could therefore lead to the harshness and humiliation problems mentioned above. Hence where proponents of LE see the choice/circumstance divide as a pre- 
cise tool for identifying fair distributive outcomes, relational egalitarians will be more prone to viewing it as potentially harsh toward those in difficult situations. They will be apt to see the institutionalization of the choice/circumstance distinction as a significant threat to equal respect, and therefore a departure from an egalitarian ethos.

This is extremely important for the justification of public insurance. Proponents of LE might legitimately fear that public insurance may lead to unfair results by compensating for bad voluntary decisions. However, relational egalitarians focus on the goal of maintaining and sustaining equal relations, and would therefore be more willing to put aside worries about 'lazy' individuals profiting from unemployment benefits. They are able to do so precisely because they can accept some 'losses' in terms of fairness for the sake of social equality. Public insurance can be justified on an equal-respect basis and not simply on a fairness basis. Hence relational egalitarians will more easily see public insurance schemes as fitting within an egalitarian project.

One way to extend this argument a little further here is to say that we need a conception of egalitarian justice that is sensitive to the expressive function of social institutions, i.e. the way they carry meanings and send various messages, and not only to their distributives consequences (Garrau and Laborde 2015; Schemmel 2012; Néron 2014). ${ }^{15}$ As Schemmel argues, the humiliation and harshness problems emerge partly because LE struggles to account for the way social institutions create or perpetuate inequalities between individuals - and especially how institutions treat individuals, as opposed to the distributive outcomes they bring about. This is what Anderson and Wolff are suggesting in their critiques of LE. They are trying to draw attention to how the institutionalization of the choice/circumstance distinction through a responsibility-assessment mechanism would negatively impact on the way some

\footnotetext{
${ }^{15}$ See Sunstein (1996) for a famous account of the expressive nature of institutions.
} 
people are treated by institutions.

This argument about the expressive function of institutions fits especially well with our analysis. Public insurance schemes are more than strict risk-management devices. They create specific moral relations among individuals and can potentially send a powerful message of equality. Policyholders become part of a community of insureds: they face uncertainty together and are collectively liable for the losses experienced by any one member of the community. ${ }^{16}$ As such, insurance provides a concrete framework as well as a normative vocabulary that individuals use to address each other, and which determines the kind of arguments they may use and how they may use them.

In other words, public insurance furnishes a social grammar that allows citizens to make equality claims. This grammar is visible in the various ways that claims for compensation within a public insurance system are framed and addressed to other policyholders. Entitlements to compensation no longer stem from charity or means-tested investigation. Such entitlements are the direct consequence of belonging to a specific community, the insurance pool - namely the state in the case of public insurance. This relational egalitarian context thereby constitutes a source of social reform and improvement since it spells out a logic of equality of standing among policyholders, offering them arguments in favor of strengthening such equality (e.g. calls for the contraceptive pill or abortion costs to be covered have been central to the struggle for gender equality).

This argument is implicit in Stone's account, in which she sees insurance as a vehicle for remedying inequalities (Stone 1999-2000, p. 40). She argues that we need to distance our-

\footnotetext{
16 It might be argued that actuarial fairness proper to insurance jeopardizes this community. Two things should be noted. Firstly, actuarial fairness does not undermine the existence of the community of insureds, it simply bends the conditions for cooperation in a certain direction. Secondly, there may be ways to regulate insurance other than those based on actuarial fairness, while still preserving the main actuarial features (e.g. overall calculation of risks without practicing redlining or certain kinds of risk classification). For more on this question, the reader can refer to Landes (2014).
} 
selves from conservative views that tend to see insurance uniquely through the lens of moral hazards, and urges us to view public insurance as providing a set of moral opportunities, one of them being to fight inequality. In her account, public insurance sends a powerful message of equal membership, even if it sometimes trumps individual responsibility.

Conversely, an insurance scheme modulated by a responsibility-tracking system would send a rather ambiguous message to unemployed workers and sick persons, hence the harshness and humiliation objections. From a relational point of view, however, though responsibility-tracking measures might constitute an improvement in terms of the fairness of distributive outcomes, they would nonetheless fail to treat individuals with equal respect, a tension that relational egalitarianism resolves by coming down in favor of equal respect.

With these remarks in mind, we are better equipped to grasp how Stone's notion of a 'community of insureds' has a deeply egalitarian meaning. And we argue that relational notions of equality better capture this meaning than luck egalitarian ones. A community of insureds is not simply a community of luck-immune individuals, it is also a community of people standing as equals. Institutions assuring citizens against the risk of suffering dismissal or sickness partly aim to secure them specific goods, but also represent a way to treat them with equal respect. Interestingly, Heath would describe such a community of insureds as mainly being a group of individuals bound by an efficient arrangement, thereby denying any credit to arguments based on the 'spirit of community' and inviting us not to overestimate the redistributive function of the welfare state. Our reading is different. Even if it is not based on the 'spirit of community' in a communitarian sense, a public insurance scheme funded by the state partly aims to create a community of individuals who can claim to stand as equals. Hence, even if it is not purely redistributive, as Heath rightly notices, it is nonetheless egalitarian. 


\section{Relational Egalitarianism as an Explanatory Strategy}

As a tool for policymaking, public insurance may be interpreted as part of a 'compromise' between the wealthy and less affluent classes (Heath 2011). It is worth pointing out here that a narrative based on such a compromise presupposes two things: (1) that difficulties involved in tracking individual choice and responsibility have been put aside by solving systemic problems of risk allocation with an institutionally coercive solution: public insurance (Ewald 1986); and (2) that such a solution was implemented because of the regrettable effects of inequalities on society as whole: class warfare, public health costs, etc., as emphasized by literature that deals with the adverse individual and social consequences of inequality (Glyn and Miliband 1994; Wilkinson and Pickett 2010).

LE does not seem well equipped to make sense of both points. As we have already mentioned, this is because LE tends to neglect the importance of adopting a systemic point of view because of its over-personalization of situations and circumstances. It is also because proponents of LE ultimately focus on fairness. Therefore, inequalities that stem from choice are just and should not be compensated. Reversely, those inequalities that should be compensated ought to be so because they are unfair. It is thus harder to condemn inequalities for their broader effects on society as a whole, since doing so does not follow on from a commitment to fairness. From a relational perspective, however, the attempt to take a step back from an over-focalization on the fairness of distributive outcomes makes it is easier to condemn inequalities, not necessarily for being unfair, but nonetheless for being wrong because of the negative consequences they have on society as a whole, for example. ${ }^{17}$

Here again, these various instrumental reasons for taming inequalities fit especially well with the relational egalitarian ethos. And they also fit well with the relational attempt to

\footnotetext{
17 This is the distinction between telic and deontic egalitarianism (O’Neil 2008).
} 
articulate claims made by real egalitarian movements.

This is not our goal within the scope of this paper. Our claim is that in an attempt to build a credible reconstruction of the growth of public insurance and the welfare state, the ability to make sense of 'instrumental' reasons to fight inequalities should not be underestimated. Many institutional changes associated with the welfare state aim to lessen inequalities in such a way that they are not viewed as intrinsically unfair, but as undesirable because of the detrimental effects they have on other important social goods we care about: higher levels of health and happiness, social cooperation, the natural environment, economic and financial stability, etc. These reasons shed light on the growth of the welfare state and the political gains made by workers, feminists (for instance). And some components of relational egalitarianism - its commitment to building the conditions for equal social relationships, its departure from an over-focalization on fairness and its broader commitment to an egalitarian ethos suggest that it is better equipped to provide us with a fruitful account of those instrumental reasons for reducing inequalities.

\section{Conclusion}

This article offered a discussion of Heath's challenge to redistributive and communitarian accounts of public insurance and the welfare state and underlined the strengths of efficiencybased arguments. We presented additional arguments on the shortcomings of a major redistributive theory (LE) in explaining and justifying public insurance. We have suggested that a different but egalitarian framework could fulfil this double function (namely relational egalitarianism). We also argued that the study of public insurance sheds light on and magnifies some of the problems that LE typically faces.

In fine, insurance, especially public insurance, may be seen as forging and spreading a 
social grammar defined as a set of rules for apprehending particular social issues and addressing claims to each other in regard to these issues. One aspect of this is the function of insurance and public insurance as a tool for governance. This dimension underlines Stone's account. And this aspect is particularly visible, for instance, in current debates on public health. The fact that individuals are part of a 'community of insureds' helps us to understand the way in which debates on obesity, smoking and other lifestyle diseases are framed. Often such debates are understood as expressions of background paternalism or conformism.

However, there is another way to look at this issue. When claims within a public insurance scheme are made in order to incentivize individuals to exercise more, eat less in general or reduce their fat intake, such claims are expressed by individuals who are co-liable for the costs implied by the lifestyles of others. They are often interpreted as intrusion into other people's lives or abusive interference motivated by a perfectionist ideal. These interpretations miss the main point, namely that such demands are expressed from within a community of interests by individuals who are co-responsible for the costs and, as such, may be seen as having a legitimate interest in expressing preferences about other people's lifestyles.

Our argument can be framed as follows: public assurance might not be purely egalitarian in the sense of not being redistributive, but it is nonetheless partly egalitarian. A community of insureds should be partly understood as a community of individuals that stand as equals, because a complex web of insurance schemes supports citizens when the time comes to formulate claims of equal standing. 


\section{Acknowledgments}

Authors wish to thank for their comments and support Elizabeth Anderson, Ryoa Chung, Joseph Heath, Nils Holtug, Karsten Klint Jensen, Carl Knight, Kasper Lippert-Rasmussen, Jyri Liukko, Chris MacDonald, Martin Marchman, Morten Nielsen, Pedro Rosa Dias, Shlomi Segall, Daniel Weinstock. Xavier Landes was funded by The Danish Council for Independent Research, section humanities (FKK) [grant 10-080448]. 


\section{References}

Anderson, Elizabeth. 1999. What is the point of equality? Ethics 109 (2): 287-337.

Anderson. Elizabeth. 2009. Toward a non-ideal, relational, methodology for political philosophy: Comments on Schwartzman's challenging liberalism. Hypatia 24 (4): 130-145.

Anderson. Elizabeth. 2010. The Imperative of integration. Princeton, NJ: Princeton University Press.

Anderson. Elizabeth. Forthcoming. Thomas Paine's 'agrarian justice' and the origins of social insurance. In Ten neglected classics of philosophy, ed. Eric Schliesser. Oxford: Oxford University Press.

Baumol, William J. 1952. Welfare economics and the theory of the state. London: Longmans, Green and Co.

Baumol, William. 1972. On taxation and the control of externalities. The American Economic Review 62 (3): 307-322.

Beito, David T. 2000. From Mutual Aid to the Welfare State. Chapel Hill, NC: The University of North Carolina Press.

Cordery, Simon. 2003. British Friendly Societies, 1750-1914. New York, NY: Palgrave Macmillan.

Dworkin, Ronald. 2002. Sovereign Virtue: The Theory and Practice of Equality. Cambridge, MA: Harvard University Press.

Ewald, François. 1986. L'État providence. Paris: Grasset. 
Ewald, François. 1996. Histoire de l'État providence. Paris: Grasset.

Fourie, Carina. 2012. What is social equality? An analysis of social equality as a strongly egalitarian ideal. Res Publica 18(2): 107-126.

Fourie, Carina, Fabian Schuppert, and Ivo Walliman-Hellmer. 2015. The nature and distinctiveness of social equality: An introduction. In Social equality: On what it means to be equals, eds. Carina Fourie, Fabian Schuppert, and Ivo Walliman-Hellmer, 1-16. Oxford: Oxford University Press.

Garrau, Marie, and Cécile Laborde. 2015. Relational equality, non-domination and vulnerability. In Social equality: On what it means to be equals, eds. Carina Fourie, Fabian Schuppert, and Ivo Walliman-Hellmer, 65-86. Oxford: Oxford University Press.

Gladwell, Malcolm. 2005. The moral-hazard myth: the bad idea behind our failed health-care system. The New Yorker, August 29.

Glyn, Edward, and David Miliband. 1994. Paying for inequality: The economic cost of social injustice. London: Rivers Oram Press.

Goodin, Robert E. 1988. Reasons for welfare: the political theory of the welfare state. Princeton, NJ: Princeton University Press.

Goodin, Robert E. 1998. Social welfare as a collective social responsibility. In Social welfare and individual responsibility, eds. David Schmidtz, and Robert E. Goodin, 97-195. New York, NY: Cambridge University Press.

Heath, Joseph. 2011. Three normative models of the welfare state. Public Reason 3 (2): 1343.

Hurley, Susan. 2003. Justice, luck, and knowledge. Cambridge, MA: Harvard University Press.

Kibe, Takashi. 2011. The relational approach to egalitarian justice: a critique of luck egalitari- 
anism. Critical Review of International Social and Political Philosophy 14 (1): 1-21.

Knight, Carl. 2005. In defence of luck egalitarianism. Res Publica. 11 (1): 55-73.

Knight, Carl. 2009. Luck egalitarianism: Equality, responsibility, and justice. Edinburgh: Edinburgh University Press.

Landes, Xavier. 2013a. Insurance. In Encyclopedia of corporate social Responsibility, eds. Samuel Idowu, Nicholas Capaldi, Liangrong Zu, Ananda Das Gupta, 1433-1440. New York, NY: Springer.

Landes, Xavier. 2013b. Insurance underwriting. In Encyclopedia of corporate social responsibility, eds. Samuel Idowu, Nicholas Capaldi, Liangrong Zu, Ananda Das Gupta, 1440-1448. New York, NY: Springer.

Landes, Xavier. 2013c. The normative foundations of (social) insurance: technology, social practices and political philosophy. Comparative politics and public philosophy lab. Torino: Centro Einaudi.

Landes, Xavier. 2014. How fair is actuarial fairness? Journal of Business Ethics. doi: 10.1007/ s10551-014-2120-0

Marx, Karl. 1993. Grundrisse. New York, NY: Penguin Classics.

Moss, David A. 2002. When all else fails: Government as the ultimate risk manager. Cambridge, MA: Harvard University Press.

Moss, David A. 2007-2008. Risk, responsibility, and the role of government. Drake Law Review 56 (2): 541-559.

Néron, Pierre-Yves. 2014. Egalitarianism and executive compensation: A relational argument. Journal of Business Ethics. doi: 10.1007/s10551-014-2312-7

O’Neil, Martin. 2008. What should egalitarians believe? Philosophy and Public Affairs 36 (2): $119-156$. 
Okun, Arthur M. 1975. Equality and efficiency: The big tradeoff. Washington DC: The Brookings Institution.

Rosanvallon, Pierre. 2013. La société des égaux. Paris: Seuil.

Scheffler, Samuel. (2010). Equality and tradition: questions of values in moral and political theory. Oxford: Oxford University Press.

Schemmel, Christian. 2012. Distributive and relational equality. Politics, Philosophy and Economics 11 (2): 123-148.

Segall, Shlomi. 2007. In solidarity of the imprudent: A defense of luck egalitarianism. Social Theory and Practice 33 (2): 177-198.

Segall, Shlomi. 2010. Health, luck, and justice. Princeton: Princeton University Press.

Shapiro, Daniel. 2007. Is the welfare state justified? New York, NY: Cambridge University Press.

Stone, Deborah. 1999-2000. Beyond moral hazard: insurance as moral opportunity. Connecticut Insurance Law Journal 6 (1): 11-46.

Sunstein, Cass. 1996. On the expressive function of law. University of Pennsylvania Law Review 144 (5): 2021-2053.

Voigt, Kristin. 2007. The harshness objection: Is luck egalitarianism too harsh on the victims of option luck? Ethical Theory and Moral Practice 10 (4): 389-407.

Wilkinson, Richard, and Kate Pickett. 2010. The spirit level: Why equality is better for everyone. London: Penguin.

Wolff, Jonathan. 1998. Fairness, respect, and the egalitarian ethos. Philosophy and Public Affairs 27 (2): 97-122.

Wolff, Jonathan. 2010. Fairness, respect and the egalitarian ethos revisited. The Journal of Ethics 14 (3-4): 335-350. 